\title{
Assistive and Smart Manufacturing Systems: Implications for Augmented Workplaces
}

\author{
David M. Savino \\ Ohio Northern University
}

Various assistive methods have been applied to support and enhance the manufacture of goods in assembly work contexts. In addition to greatly increasing both quantity and quality results in production environments for most workers, these systems have also been employed successfully with other workers such as elderly and impaired persons. The variety of production methods used include motion recognition and projection to elements based on game design which is also known as gamification. This study is a discussion of these various production methods and their applications and the implications for improved worker results achieved through enlightened production training techniques.

\section{INTRODUCTION}

There's a not too subtle revolution taking place in the world of manufacturing and assembly. Over the last few years a sophisticated system of automation has swept through the global world of manufacturing goods. This technology is simple, efficient and facilitates a high degree of production accuracy that achieves consistently positive results. The world of assistive smart manufacturing is the blending of manual manufacturing techniques with augmented reality and gaming elements that helps create diverse and complex products that are simple to make and allows for standardization. The result is more productive systems, high quality products, safer working conditions and a platform for the transfer of learning that has major implications for Human Resources practitioners in the field of the training and development of all kinds of employees.

The recent transformation of automated production in many ways creates a strangely parallel production revolution headed by Frederick Taylor and others in the Scientific Management movement over a century ago. In his time Taylor worked to create a manufacturing system so detailed and prescriptive that any basic worker could understand and easily practice to create amazing productivity outcomes. His extreme division of labor and detailed job design revolutionized manufacturing that achieved high levels of productivity, high quality results and cost efficiency. The current wave of Smart Manufacturing achieves similar results based on job details and procedures that are generated by automated and virtual means. The "Fourth Industrial Revolution" as some have called it is a fusion of technologies across several worlds which is creating tremendous capabilities and impacts in manufacturing, economic systems and human endeavors defined in terms of speed, connectivity and change (Huffington, 2016). The advent of Smart Manufacturing Systems (SMS) can either be applied as a new system using high technology as the base or blending it into existing systems that were designed based on more traditional physical means. The value of SMS is to be agile to respond quickly to adapt 
new production techniques that do not significantly disrupt ongoing manufacturing processes (Jung et al., 2016).

\section{THE TRADITIONAL PRODUCTION CONTEXT}

Assembly and production line work is generally repetitive and lends itself to the great possibly of errors which leads many to consider moving to completely automated systems (Korn et al., 2014). While many simple assembly type work can easily be automated, many types of assembly work require tasks that may not be totally repetitive, may require adjustments during the process due to the nature of the particular job where human touch is required or for economic reasons when the lot size may not justify total automation. Therefore, as a general rule larger lot sizes with simple and repetitive processes can be done through automation (Korn, et al., 2012).

The transfer of knowledge in any kind of training is essential if we expect well trained employees to carry out assigned tasks related to their jobs. Training and instructional design should be developed on a system of needs assessment based on organizational, person and task expectations (Noe et al., 2016). In basic manual manufacturing and assembly these assessments and successful results are based on meeting the expectations expressed by Human Resources on behalf of the organization, through individual capabilities of human capital and the task at hand. The usual procedure of training is accomplished by having experienced workers teaching new employees by personal oversight or through the use of printed instructions (Funk et al., 2015). The expectation is that the growing demand for more specialized and individualized products will still require manual assembly procedures that are complex (Korn, 2012). In order to facilitate the continued need for manual assembly that is expected to be efficient and safe with high quality products being produced, new and exciting assembly methods are being accomplished by a variety of smart manufacturing techniques using augmented reality, assistive systems based on motion recognition, gamification and in-stu image projection (Hahn, 2015; Funk, 2015; Zhou, 2011 and Korn, 2014). The increased need for assistive systems involved in smart manufacturing set the tone by generating three paradigms for productive designs that deal with scalability of competence and process, limited information at the appropriate time and increased interest on the part of the worker related to motivation and work enjoyment with the right information, in the right place at the right time (Ruther et al., 2013).

\section{STATE OF THE ART OF APPLIED ASSISTIVE SYSTEMS}

Traditional methods of production and associated training techniques have relied on the use of a prescriptive set of instructions that were to be followed consistently once they were learned by the worker. These detailed set of guidelines were usually developed in a written format that both the trainer and the worker needed to understand and apply. However, because of certain complexities now seen in an ever changing work environment along with potentially prohibitive costs of human assistance, interactive assistive instruction systems have been successfully applied based on technological advances utilizing displays, in-situ projection and gamification (Funk et al., 2016; Korn, 2015).

Since its early developments seen in the 1990s, assistive technology is recognized to be an interdisciplinary field based on elements of engineering, computer science as well psychology and ethics (Cook \& Hussey, 1995; Korn, 2014). As seen in Figure 1 below assistive systems involve a complex set of issues in each of the relevant disciplines that not only look at the technical aspects of the system but also at the human and moral issues involved (Korn, 2014). 


\section{FIGURE 1 \\ DISCIPLINES RELATED TO CONTEXT-AWARE ASSISTIVE SYSTEMS \\ (Oliver Korn, 2014)}

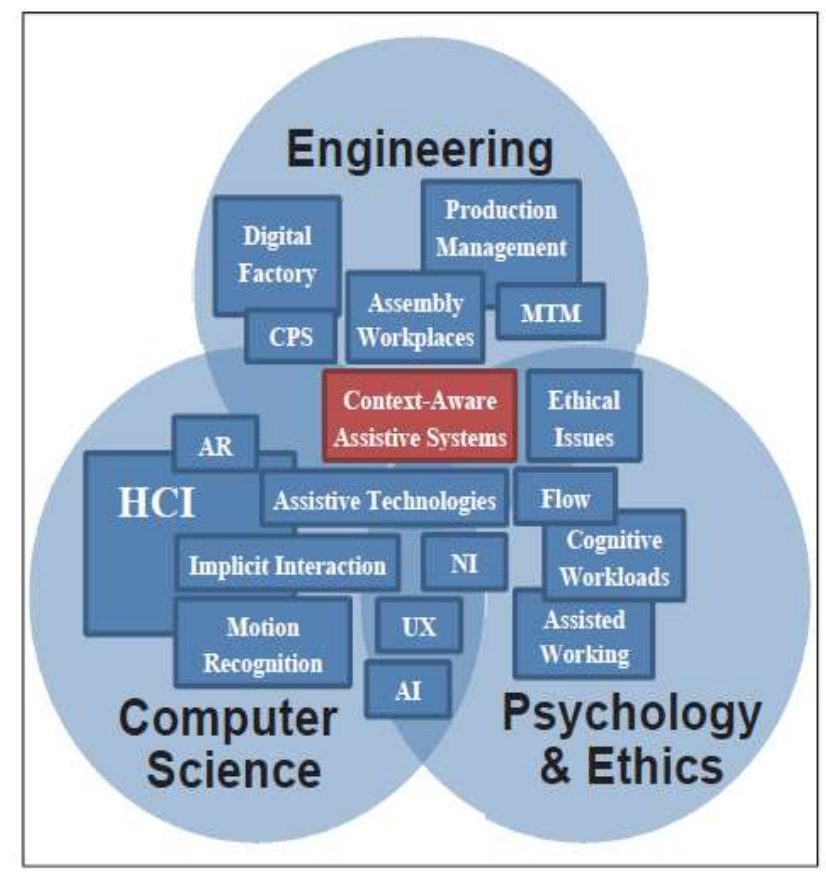

With its development initially targeted at individuals with cognitive and motor challenges, assistive technology is now easily seen in various applications such as in route guidance systems in cars, Google glass wearables and in manufacturing and product assembly (Korn, 2014). While these are very exciting manufacturing technologies that are revolutionizing product assembly and manufacturing, they are by no means new to the world of production. An early version of light projected and worker interaction was first seen in 1991 based on Wellner's Digital Calculator where a camera was used to see where the user was pointing and then ten years later with the Everywhere Displays Projector that made office spaces interactive (Wellner, 1991; Pinhanez, 2001). More recently the patented Light Guide System developed by OPS Solutions uses projection without interaction (Korn, 2014). In addition, early examples of repurposing gamification outside of game applications came in 2007 related to cancer treatment for children and in 2010 for therapeutic purposes (Kato, 2008; Korn, 2012).

\section{ASSISTIVE TECHNOLOGIES AS APPLIED TO HUMAN ACTIVITY}

One of the greatest advances in the area of work was the eventual routine interaction of human work and technology in the machine age. The long standing use of technology in engineering and production management was designed to assist healthy workers who were "impaired" when it came to heavy weights and dangerous conditions and substances (Korn, 2014). The assistance and support provided by technology in the work environment extends the human condition and its capacities in cognitive and physical endeavors. When this person-machine interaction takes place certain behavioral patterns emerge that should be analyzed and interpreted to generate a proper interface as related to such elements as activity, human, context and assistive technology as defined by the Human Activity Assistive Technology Model (HAAT) (Cook \& Hussey, 1995). In work environments the human is the intrinsic enabler and the assistive technology is defined as the extrinsic enabler (Korn, 2014). 
Manual assembly and basic production have been the basis of industrialized success and remain so today. The key issue is determining the proper balance between those activities that can be fully automated which require manual human oversight with those situations where special conditions require human interaction that can be made more efficient, safe and with better levels of quality as a result (Funk, 2015). Through various modes of interaction the user is able to interact with assistive and augmented systems that allow the user to extend their abilities regardless of personal ability or condition (Rüther, 2014).

\section{TRAINING IMPAIRED PERSONS THROUGH ASSISTIVE SYSTEMS}

One of the most interesting applications of assisted and smart manufacturing is the application of these techniques in the training and the ultimate work output of impaired individuals as defined by age, physical or mental limitations. The designation of the term impaired individuals in based on a document developed by the United Nations General Assembly (Hendricks, 2007). Another consideration in dealing with worker limitations relates to employees from other countries who speak different languages. Therefore, training and production procedures presented via assistive methods go beyond traditional means which many times does not provide desired work outputs either in terms of quality or quantity (Hahn, 2015). The use of assistive manufacturing techniques have proved to be very beneficial to workers with limitations. Based on the need for assembly workers and the effort on the part of society to more fully integrate impaired workers into everyday work process, the use of in-situ projection in training and work outcomes have shown great promise (Funk, 2015). The use of assistive systems has consistently shown the potential of substantially increasing the inclusion of impaired workers as contributing, productive members in contracted work sometimes called sheltered work environments (Korn, 2013; Funk, 2015). Also, the labor market for manual work to be done by impaired individuals is an important part of the economy because it has implications that are therapeutic in nature for certain citizens, helps support legal obligations of employing people in employing those handicapped or impaired and for benefits derived from efficiencies achieved through outsourcing (Korn, 2013).

\section{ASSISTIVE TECHNOLOGY FOR ELDERLY EMPLOYEES}

Because of the great recession of about a decade ago along with increasing lifespans, many workers in Europe, Japan and the United States are prolonging their work careers in greater numbers to either add to their financial resources for retirement or they just prefer to continue to work for the continued challenges. With prolonged careers as a reality, there is a generally believed correlation between age and the increased impairment (Korn, 2014). Some refer to workers beyond the age of 60 as elderly where some suffer from a measured reduction in memory and learning abilities (Satre, et al., 2006). While older workers may not consider themselves impaired because some deficits in performance are age appropriate, in work environments such deficiencies could lead to more consistent errors and increased production time (Ikeda et al., 2009). The use of assisted and smart manufacturing techniques is a great way to counteract demographic challenges and facilitate the further development of skills and the empowerment of elderly and impaired individuals to achieve greater results in more complex production situations with lower error rates (Brach, 2012).

\section{ASSISTIVE SYSTEM OUTCOMES}

Numerous studies have been done to evaluate the outputs achieved by workers using assistive manufacturing systems. A systematic review of these various studies yield generally positive results based on success indicators such as ease of use, helpfulness, joyfulness/satisfaction, increased accuracy, independence of work and enhancement of skills (Buttner et al., 2016; Sauer, 2010). Several different types of assembly operations have been studied to see the value of assistive technology. Some of the types 
of operations were health care instrument sterilization, automotive spot welding, general automotive manufacturing, manual order picking, basic assembly jobs, school and vocational training (Sauer, 2010).

A field study conducted in Germany at the Beschutzende Werkstatte Heilbronn (BWH) was undertaken to observe impaired workers using assistive technology to assess processing orientation, work time and error rates (Korn, et al., 2013). This was a German sheltered work facility that employed approximately 1000 workers with various forms of impairment. After being contacted by the organization's board and written consent was given by the worker or their legal guardian, 81 workers were selected for the study Langheinrich et al., 2013). A pre-study helped determine the test subjects, a baseline of the subjects understanding of the work involved and expected output as related to assembling a product made with Lego pieces. For the actual study the workers were divided into two test groups; those with no assembly augmentation and those using in-situ projection (Korn, 2014). After observing assembly of products based on the two augmentation methods and a questionnaire being administered, the subjects were assessed on their respective performances based on method, time measurement and quality. Overall, the results showed that while the in-situ projection method yielded faster production times, error rates were slightly higher (Korn et al., 2013). The main difference seemed to come down to the ease of following projected prompts and seeing part images to be assembled versus constantly looking at instructions of assembly. Regardless, many of the workers did have difficulties on a cognitive level which still need to be addressed in the design of future work environments for impaired workers.

Another study was conducted to explore the effect of in-situ instructions versus printed pictorial instructions showed very promising results for assistive manufacturing for impaired workers in a sheltered work environment. By observing the work of 15 cognitively impaired workers the results indicated that more complex products could be assembled three times faster with $50 \%$ less errors (Funk et al., 2015). In addition, while pictorial instructions have been more commonly used to train impaired workers over the years with very good results, the introduction of in-situ assistance proved to be more productive and in some ways more preferred by the workers on a personal enjoyment level when their supervisors reported that the workers were asking to work in the workplace with lights again (Funk, 2015, Pierce 1994).

Other projection or light guided systems have shown some promise in specific applications. For example, a project in the oil and gas industry was greatly benefited as a result of using projected instructions for assembly when new workers were needed to be hired that required extensive training (Ryznar, 2016). This system of projection without interaction was utilized and successfully addressed key issues such as safety, productivity, performance, quality and cost (Ryznar, 2016; Korn et al., 2014). In varied manufacturing situations the OPS patented Light Guide System has shown significant positive results in assembly environments with errors reduced by 80 percent, production time reduced by 40 percent and throughput increased by over 80 percent (Ryznar, 2016).

\section{CONCLUSION}

As reported workers generally develop a routine in their tasks that serve them well as far as achieving the desired levels of outputs in a timely manner with acceptable amounts of errors. It appears that workers of all types have benefited from assistive method assembly and manufacturing. The results reported from various types of production environments yield convincing results that assistive manufacturing will continue to grow in its applications and wide spread usage. While the initial emphasis of this research was to search for ways to improve general work environments through assistive systems, the results are obviously well beyond those typical work environments. Workers impaired either through cognitive, physical or age conditions have consistently shown significant results where methods of assistive manufacturing and assembly are utilized. While some reported that augmented systems has a catalytic effect with concrete results to back their claims, others were more than eager to promote the various augmented systems that not only increased productivity but also provided personal reactions of satisfaction and work enjoyment (Korn et al., 2013). Assistive systems in production thus provide a regulation on production and a quality gate (Korn, et al., 2015). A great deal can be said able what 
assistive and augmented systems can mean to impaired employees to support independent work, building confidence and promoting inclusive employment (Baechler et al., 2016). Empowerment is sometimes an overused work in reported behaviors and outcomes in the workplace, but in the area of supporting and genuinely expanding the opportunities for satisfaction and success of the impaired in the workplace its use seem more than appropriate.

\section{REFERENCES}

Baechler, L., Baechler, A., Funk, M., Autenrieth, S., Kruell, G., Hoerz, T., \& Heidenreich, T. (2016). The Use and Impact of an Assistance System for Supporting Participation in Employment for Individuals with Cognitive Disabilities. In International Conference on Computers Helping People with Special Needs. Springer International Publishing. July, 329-332.

Brach, M., \& Korn, O. (2012). Assistive technologies at home and in the workplace-a field of research for exercise science and human movement science. European Review of Aging and Physical Activity, 9(1), 1.

Büttner, S., Funk, M., Sand, O., \& Röcker, C. (2016). Using Head-Mounted Displays and In-Situ Projection for Assistive Systems-A Comparison. In Proceedings of the 9th ACM International Conference on PErvasive Technologies Related to Assistive Environments. ACM(Vol. 8).

Cook, A. M., \& Hussey, S. M. (1995). Seating and positioning systems as extrinsic enablers for assistive technologies. Assistive Technology: Principles and Practice, 235-310.

Funk, M., Bächler, A., Bächler, L., Korn, O., Krieger, C., Heidenreich, T., \& Schmidt, A. (2015). Comparing projected in-situ feedback at the manual assembly workplace with impaired workers. In Proceedings of the 8th ACM International Conference on PErvasive Technologies Related to Assistive Environments (p. 1). ACM., July.

Funk, M., Kosch, T., \& Schmidt, A. (2016). Interactive Worker Assistance: Comparing the Effects of InSitu Projection, Head-Mounted Displays, Tablet, and Paper Instructions. Proceedings of the 2016 ACM International Joint Conference on Pervasive and Ubiquitous Computing, 934-939.

Hahn, J., Ludwig, B., \& Wolff, C. (2015). Augmented reality-based training of the PCB assembly process. In Proceedings of the 14th International Conference on Mobile and Ubiquitous Multimedia. ACM., November, 395-399.

Hendricks, A. (2007). UN Convention on the Rights of Persons with Disabilities. Eur. J. Health L., 14, 273.

Huffington, Arianna (2016). The Fourth Industrial Revolution Meets the Sleep Revolution, Huffington Post, Jan 28, 2016. accessed through http://www.huffingtonpost.com/arianna-huffington/fourthrevolution-sleep-revolution_b_9092496.html on August 22, 2016.

Ikeda, N., Murray, C. J., \& Salomon, J. A. (2009). Tracking population health based on self-reported impairments: Trends in the prevalence of hearing loss in US adults, 1976-2006. American Journal of Epidemiology, kwp097.

Jung, Kiwook, Morris, Katherine, Lyons, Kevin W., Leong, Swee and Cho, Hyunbo. (2016) Performance Challenges Identification Method for Smart Manufacturing Systems, Systems Integration Division Engineering Laboratory, NIST.

Kato, P. M., Cole, S. W., Bradlyn, A. S., \& Pollock, B. H. (2008). A video game improves behavioral outcomes in adolescents and young adults with cancer: a randomized trial. Pediatrics, 122(2), e305-e317.

Korn, O., Schmidt, A., \& Hörz, T. (2012). Assistive systems in production environments: exploring motion recognition and gamification. In Proceedings of the 5th international conference on pervasive technologies related to assistive environments (p. 9). ACM., June.

Korn, O., Brach, M., Schmidt, A., Hörz, T., \& Konrad, R. (2012). Context-Sensitive user-centered scalability: an introduction focusing on exergames and assistive systems in work contexts. In $E$ Learning and Games for Training, Education, Health and Sports. Springer Berlin Heidelberg, 164-176). 
Korn, O., Schmidt, A., \& Hörz, T. (2013). The potentials of in-situ-projection for augmented workplaces in production: a study with impaired persons. In CHI'13 Extended Abstracts on Human Factors in Computing Systems. ACM., April, 979-984

Korn, Oliver (2014). Context-aware assistive systems for augmented work: a framework using gamification and projection. University of Stuttgart.

Korn, O., Funk, M., Abele, S., Hörz, T., \& Schmidt, A. (2014). Context-aware assistive systems at the workplace: analyzing the effects of projection and gamification. In Proceedings of the 7 th International Conference on PErvasive Technologies Related to Assistive Environments. ACM., May, 38.

Langheinrich, M., Schmidt, A., Davies, N., \& José, R. (2013). A Practical Framework for Ethics: The PD-net Approach to Supporting Ethics Compliance in Public Display Studies. In Proceedings of the $2 \mathrm{Nd}$ ACM International Symposium on Pervasive Displays. New York, NY, USA: ACM. doi:10.1145/2491568.2491598, 139-143.

Noe, Raymond, Hollenback, John, Gerhart, Barry and Wright, Patrick. (2016). Fundamentals of Human Resource Management. New York, NY, McGraw-Hill Education.

Pierce, K. L., \& Schreibman, L. (1994). Teaching daily living skills to children with autism in unsupervised settings through pictorial self-management. Journal of applied behavior analysis, $27(3), 471-481$.

Pinhanez, C. (2001). The everywhere displays projector: A device to create ubiquitous graphical interfaces. In Ubicomp : Ubiquitous Computing, Springer, 315-331.

Rüther, S., Hermann, T., Mracek, M., Kopp, S., \& Steil, J. (2013). An assistance system for guiding workers in central sterilization supply departments. In Proceedings of the 6th International Conference on PErvasive Technologies Related to Assistive Environments. ACM., May, 3.

Rüther, S. (2014). Assistive systems for quality assurance by context-aware user interfaces in health care and production (Doctoral dissertation, Universitätsbibliothek Bielefeld).

Ryznar, Paul. (2016). Solving the Customization Riddle in Energy Manufacturing. Augmented reality instructions for nonstandardized work can optimize the process of manufacturing and assembly, Manufacturing Engineering, found at http://www.sme.org/MEMagazine/Article.aspx?id=8589934666, accessed May 12, 2016.

Satre, D. D., Knight, B. G., \& David, S. (2006). Cognitive-behavioral interventions with older adults: Integrating clinical and gerontological research. Professional Psychology: research and practice, 37(5), 489.

Sauer, A. L., Parks, A., \& Heyn, P. C. (2010). Assistive technology effects on the employment outcomes for people with cognitive disabilities: a systematic review. Disability and Rehabilitation: Assistive Technology, 5(6), 377-391.

Wellner, P. (1991). The DigitalDesk calculator: tangible manipulation on a desk top display. In Proceedings of the 4th annual ACM symposium on User interface software and technology. ACM, November, 27-33. 